RAE-IC, Revista de la Asociación Española de Investigación de la Comunicación

vol. 9, núm. 17 (2022), 103-132

ISSN 2341-2690

Recibido el 31 de octubre de 2021

DOI: https://doi.org/10.24137/raeic.9.17.5

Aceptado el 24 de enero de 2022

(c) (1) (2)

\title{
Humor e identidad como recursos expresivos para la construcción de marca en redes sociales. El caso de Malacara
}

Humour and identity as expressive resources for brand building in social networks. The case of Malacara

Torres-Martín, José Luis

Universidad de Málaga (UMA)

jltorres@uma.es

Castro-Martínez, Andrea

Universidad de Málaga (UMA)

andreacastro@uma.es

Díaz-Morilla, Pablo

Universidad de Málaga (UMA)

EADE Universidad-University of Wales Trinity Saint David pablodmorilla@uma.es

Forma de citar este artículo:

Torres-Martín, J.L., Castro-Martínez, A. y Díaz-Morilla, P. (2022). Humor e identidad como recursos expresivos para la construcción de marca en redes sociales. RAEIC, Revista de la Asociación Española de Investigación de la Comunicación, 9(17), 103-132.

https://doi.org/10.24137/raeic.9.17.5 


\section{Resumen:}

Este trabajo se centra en el caso de Malacara, una cuenta cuya principal actividad se desarrolla en Twitter y que se ha convertido en todo un fenómeno en el panorama español. A través de la entrevista en profundidad a Lucas Melcón, la persona detrás de Malacara, y del análisis de los perfiles sociales de la marca se pretende analizar el discurso humorístico de sus publicaciones, identificar los recursos expresivos, los temas a los que recurre y describir su estrategia comunicativa digital. Los resultados indican el empleo de textos en mayúsculas imitando el habla andaluza y de imágenes de personalidades conocidas, del mundo animal y de la cultura popular como principales particularidades de su discurso, en el que la vida cotidiana y la crítica política y social tienen un gran peso. El éxito de Malacara demuestra que es posible hacer humor en el terreno digital desde la periferia construyendo una voz propia en base a las raíces vernáculas y populares.

Palabras clave: humor, redes sociales, memes, parodia, identidad, creación de contenidos, estrategia digital, comunicación, dialecto, Andalucía.

\section{Abstract:}

This work focuses on the case of Malacara, an account whose main activity is based on Twitter and which has become a phenomenon on the Spanish scene. Through an indepth interview with Lucas Melcón, the person behind Malacara, and an analysis of the brand's social profiles, the aim is to analyse the humorous discourse of its publications, identify the expressive resources and topics to which it resorts and describe its digital communication strategy. The results indicate the use of texts in capital letters imitating Andalusian speech and images of well-known personalities, the animal world and popular culture as the main features of its discourse, in which everyday life and political and social criticism play a major role. Malacara's success proves that it is possible to create humour in the digital sphere from the periphery, building one's own voice based on vernacular and popular backgrounds. 
Keywords: humour, social networks, memes, parody, identity, content creation, digital strategy, communication, dialect, Andalusia.

\section{INTRODUCCIÓN}

El humor y el desenfado se han utilizado a lo largo de los años como seña de identidad de muchas marcas, desde productos de consumo cotidiano a importantes medios de comunicación (Mogin-Martin, 2006; Valiente, 2016; Nevado, 2020). Sin embargo, el uso del humor como estrategia comunicativa ha evolucionado especialmente en la última década, principalmente como consecuencia de la expansión de Internet. Los memes y las parodias son una constante en gran parte de los contenidos que se crean y se difunden en el ámbito digital donde, a través de la copia o la reinterpretación, se logra atraer la atención de usuarios. Y es que el humor gráfico tiene la capacidad de sortear instituciones y personalidades, por muy potente y cuidada que sea su imagen pública, desde la Monarquía hasta cualquier político o representante público (Carratalá, 2015), por lo que las redes sociales aportan el contexto perfecto para su desarrollo en soportes no convencionales. Así, el humor apoyado en recursos visuales ha evolucionado desde los opinadores gráficos que, a través de sus viñetas humorísticas, se convirtieron en figuras de prestigio por su trabajo en la prensa diaria (Meléndez Malavé, 2010) hasta los creadores actuales, muchas veces anónimos, que comparten sus contenidos en la red. Plataformas como Twitter, Instagram, Twitch o TikTok (Gutiérrez Lozano, 2020; Rey, 2020) acogen en la actualidad múltiples contenidos que emplean el humor para hacerse virales (Holton y Lewis, 2011; Imlawi y Gregg, 2014), por lo que este trabajo pretende conocer las claves de una cuenta de gran éxito en redes como es Malacara.

\section{MARCO TEÓRICO}

\subsection{LAS NARRACIONES AUDIOVISUALES Y EL HUMOR EN EL ÁMBITO DIGITAL}

Las narrativas audiovisuales contemporáneas han encontrado un aliado y un vehículo idóneo en las tecnologías de la comunicación y, más concretamente, en las redes sociales. Especialmente se han beneficiado de esta circunstancia aquellas basadas en la 
copia, repetición y reinterpretación de mensajes y obras artísticas preexistentes. Las nuevas plataformas sociales las han impulsado, aunque se trate de un fenómeno ya conocido y no exclusivo del ámbito digital, al que han hecho referencia autores como Benjamin (2021), que las consideraba como aquellas "en las que la vida social es trastocada con la transversalización de un complejo aparato técnico capaz de acercar la mano del artista a la del receptor" (Morgan, 2019, p. 1). Por su parte, Julia Kristeva (1969), recogiendo los planteamientos sobre el dialoguismo de Bakhtin -compilados a su vez por Emerson (2018)-, introdujo hace más de medio siglo el revolucionario concepto de intertextualidad. Según la interpretación de González Álvarez (2003), "en su concepción general, la intertextualidad se contempla como una cualidad de todo texto entendido como un tejido de alusiones y citas y, en su visión restringida, como la presencia efectiva en un texto de otros textos anteriores" (p. 116). Genette (traducido por Prieto, 1989) fue más allá y describió cinco tipos de relaciones transtextuales en orden creciente de abstracción: de la intertextualidad de Kristeva a la architextualidad, pasando por el paratexto, el metatexto y el hipertexto. De este último término se ocupa específicamente Genette en su obra anteriormente citada, considerando como tal "a todo texto derivado de un texto anterior por transformación simple (diremos en adelante transformación sin más) o por transformación indirecta, diremos imitación" $(1989$, p. 17). Asimismo, las redes sociales han hecho que las narraciones actuales no se comprendan sin su dimensión transmedia (Jenkins, 2010) y que tiendan a atomizarse, a abreviarse - de ahí el universo de tuits, memes, clips, tiktoks, teasers, etc. - y a despojarse de todo lo superfluo para captar la atención de unas audiencias sobresaturadas de información e impactos audiovisuales (Scolari, 2020).

Como cualquier otro género, el humorístico no ha escapado a estas nuevas condiciones del paradigma comunicacional, marcadas por la globalización, los sucesivos avances tecnológicos de la sociedad actual y los cambios que han producido en las interacciones personales en términos sociológicos y comunicacionales, en los que han jugado un papel esencial las redes sociales (Camas, Valero y Vendrell, 2018). El ámbito académico de las Ciencias de la Comunicación ha abordado la relación entre el humor y las redes sociales desde múltiples puntos de vista: la comunicación política (Sierra, 2012; Fuica González, 
2013; Pérez Pereiro y Campos, 2019), la comunicación institucional y las relaciones públicas (Padilla Castillo, 2016; González Oñate y Martínez Sánchez, 2020), la publicidad y el marketing (Mosquera Álvarez e Hidalgo Albuja, 2020; Brennan et al., 2020; Akbar y El-Gohary, 2021), la creatividad (Vásquez, 2019), el periodismo y la comunicación audiovisual (Alvarado Ortega y Ruiz Gurillo, 2013; Weitz, 2016; Fraticelli, 2019), los estudios de género (Mancera Rueda, 2014) e incluso el humor en redes durante la pandemia de la COVID-19 (Sola-Morales, 2020; Kral'ovičová, 2020).

\subsection{LOS MEMES COMO FORMATO HUMORÍSTICO POR EXCELENCIA EN REDES SOCIALES}

Ballesteros (2016) ofrece una definición del término meme: "una composición verbovisual o audio-visual, de naturaleza digital que se transmite por la red, siendo susceptible de evolucionar a medida que viaja virtualmente" (p. 25). Etimológicamente, la palabra procede del vocablo griego mimeme, que significa "lo que se imita". Se utilizó por primera vez en la obra del zoólogo Richard Dawkins The Selfish Gene (1976) para enunciar su hipótesis memética de la transmisión cultural, refiriéndose a meme como "la unidad mínima de información que es posible transmitir o imitar" (Alarcón, 2017, p. 123). Sin embargo, el concepto ha ido mutando de significado con el transcurrir del tiempo; Shifman (2012) los reconoce como contenidos de diverso origen que pueden ir evolucionando a la par que son utilizados y resignificados por los usuarios. De forma más extensiva, los memes pueden ser cualquier producto que se halle en Internet y origine diferentes contenidos replicables, a través de todas sus variables: la imagen fija con o sin texto, los gif, vídeos, etc. (García Huerta, 2014). Islas (2020), por su parte, los considera "un elemento que permite entender la estructura sociocultural de los individuos inmersos dentro de una cultura digital" (p. 46). Camas, Valero y Vendrell (2018) enumeran los rasgos que caracterizan a los memes:

(1) la fidelidad con el acontecimiento a destacar, de forma que sea reconocible por los ciudadanos; (2) la fecundidad o potencialidad de transmisión, normalmente de naturaleza viral, en función del valor que la comunidad le otorgue; y (3) la facilidad para permanecer en el tiempo y el espacio de la red (Arango, 2015), a lo que añadiríamos, (4) su carácter humorístico (p. 121). 
En cuanto a las formas culturales que se integran en los memes hallamos música, tendencias de moda, frases coloquiales, fotografías, vídeos, etc., "todas ellas estructuras vivas susceptibles de ampliar su alcance" (Martínez-Rolán y Piñeiro-Otero, 2016). Aunque los memes no son nativos ni exclusivos del ámbito digital, han encontrado en plataformas como Facebook, Twitter, Instagram o YouTube unos vehículos de “propagación viral” (Hernanz y Hernanz, 2012; García Huerta, 2014) hasta convertirse en modos de expresión y participación en las comunidades digitales (Davison, 2012; Vickery, 2014).

Por último, estos textos audiovisuales abarcan un amplio abanico de temas: política (Martínez Rolán y Piñeiro Otero, 2017; Maciá y Rissotto Britos, 2020), filosofía (Alarcón, 2017), cultura (Islas, 2020), literatura (Llosa Sanz, 2020), identidad (Pérez Salazar, 2017) e incluso los discursos extremistas y de odio en las redes sociales (Pérez-Pereiro y Romay-Campos, 2020).

\subsection{HUMOR E IDENTIDAD}

La realidad diversa de nuestro país también se ha plasmado en el género humorístico. El estudio de Requejo Fraile, Velasco Molpeceres y Reguero Sanz (2016) aborda el proceso de autodeterminación de Cataluña en el humor gráfico de la prensa española. Otros, como los de Martínez-García (2009) y Anduaga (2017) se ocupan del humor en la ficción televisiva -comedia de situación y programas de entretenimiento, concretamentecomo forma de construcción de las identidades nacionales catalana y vasca, respectivamente. Sánchez-Gey (2021) se refiere al reflejo de la televisión autonómica andaluza en redes sociales, donde el humor estereotipado ocupa un lugar preeminente.

Precisamente, este ámbito de las redes sociales no ha permanecido ajeno a este empleo del humor como seña de identidad territorial. Mancera Rueda (2016) analiza el uso lingüístico del español no normativo como rasgo identitario en estos medios digitales que, paradójicamente, se caracterizan por su alcance global. Por su parte, la investigación etnográfica digital de Díaz Bizkarguenaga (2015) se centra en Facebook como herramienta para la conformación de la identidad nacional vasca, para lo que en muchas ocasiones se utiliza la sátira, la ironía o la parodia. Gil Ramírez (2018) relaciona 
el uso de vídeos humorísticos en YouTube con la comunicación política en el marco del procés catalán. Sin embargo, no existe una extensa producción académica de autores españoles al respecto del humor identitario en redes sociales, aunque el estudio de Pano Alamán y Mancera Rueda (2014) haga hincapié en la importancia del humor verbal y de construir una identidad paródica en Twitter. Álvar (1962) ya nos hablaba del atractivo del dialecto andaluz como recurso humorístico:

fluctuando entre el ímpetu revolucionario de su fonética y el conservadurismo tradicional de su sintaxis, de su fraseología, de su refranero y de su léxico, el andaluz ofrecería un equilibrio armónico y casi taumatúrgico que sería la causa más patente de la seducción, el encanto y la gracia del hablar de las gentes béticas (p. 227).

Sin embargo, Narbona Jiménez (1986, p. 233) expresa la dificultad que ha supuesto tradicionalmente la unificación de la sintaxis coloquial andaluza: "que está por hacer la gramática de la lengua coloquial es algo reconocido por todos", afirma. Pese a este problema, Moreno (2008) refleja la necesidad de realizar una reivindicación de la cultura andaluza en los siguientes términos:

Que cuando nos encontramos en pleno siglo XXI todavía exista debate no solo sobre los contenidos de la cultura andaluza, sino que sea necesario defender la existencia de esta, y de Andalucía como hecho cultural, es una realidad que constituye uno de los obstáculos fundamentales para la toma de conciencia de los andaluces como pueblo, y por tanto, un lastre para desplegar nuestras potencialidades como tal, tanto en el ámbito económico, como en el social y el político (p. 7).

\section{OBJETIVOS Y METODOLOGÍA}

El objetivo principal de la presente investigación consiste en analizar el discurso humorístico de las publicaciones de Malacara en redes sociales. Como objetivos secundarios, se pretenden identificar los recursos expresivos y los temas a los que recurre dicho autor en las publicaciones que postea en sus distintos perfiles; por último, 
realizar una descripción de la estrategia comunicativa digital empleada por Lucas Melcón, creador de dicha marca.

Con respecto a la metodología, está diseñada como un estudio de caso (Wimmer y Dominick, 1996), puesto que se trata de "una investigación empírica que estudia un fenómeno contemporáneo dentro de su contexto de la vida real, especialmente cuando los límites entre el fenómeno y su contexto no son claramente evidentes" (Yin, 1994, p. 13). En él se emplean dos herramientas metodológicas distintas:

- el análisis de contenido de los perfiles en redes sociales del proyecto (Facebook, Twitter e Instagram), siguiendo los postulados generales de Bardin (1991) y los del análisis de contenido de las comunicaciones de Colle (2011). Se ha realizado una monitorización en tres fases: en primer lugar, se han obtenido los datos globales de los tres perfiles; después se ha realizado una comparativa de la actividad de las distintas cuentas entre el 17 de octubre y el 1 de diciembre de 2021 para conocer sus índices de actividad más reciente; por último, se ha procedido a monitorizar la actividad de la cuenta de Twitter durante el año 2021. Para obtener los datos se han empleado las herramientas Google Trends, Social Blade, Twitonomy, Fanpage Karma y las propias analíticas de Twitter, además del análisis manual de las publicaciones en Twitter aplicando una ficha de vaciado (tabla 1). Para la elaboración de esta tabla se han tenido en cuenta los trabajos previos de Castro-Martínez y Díaz-Morilla (2021) y Castro-Higueras, Torres-Martín, Carballeda-Camacho y Aguilera-Moyano (2021) para el análisis de la red social y de Knobel y Lankshear (2006, p. 218) para la tipología de los memes de Internet; 
Tabla 1. Ficha de análisis de contenido en Twitter.

\begin{tabular}{|c|c|c|}
\hline \multirow{12}{*}{ Recursos formales } & \multirow{8}{*}{$\begin{array}{c}\text { Elementos } \\
\text { audiovisuales }\end{array}$} & Imagen/Vídeo \\
\hline & & Gráficos/Rótulos/Efectos \\
\hline & & Audio \\
\hline & & Texto \\
\hline & & Emoticonos \\
\hline & & Gif \\
\hline & & Enlaces \\
\hline & & $\begin{array}{l}\text { Memes (política/comentario social/bromas de } \\
\text { diversas subculturas/ humor absurdo/ } \\
\text { propagación de bulos/otros) }\end{array}$ \\
\hline & \multirow{4}{*}{$\begin{array}{l}\text { Recursos para } \\
\text { la interactividad }\end{array}$} & Etiquetas \\
\hline & & Llamadas a la acción \\
\hline & & Menciones \\
\hline & & Encuestas \\
\hline \multirow{4}{*}{ Recursos narrativos } & \multicolumn{2}{|l|}{ Tipo de narrador } \\
\hline & \multicolumn{2}{|c|}{ Lenguaje empleado } \\
\hline & \multicolumn{2}{|c|}{ Personajes principales y secundarios } \\
\hline & \multicolumn{2}{|c|}{ Relación entre texto e imagen } \\
\hline
\end{tabular}

Fuente: Elaboración propia a partir de Castro-Martínez y Díaz-Morilla (2021), CastroHigueras, Torres-Martín, Carballeda-Camacho y de Aguilera-Moyano (2021) y Knobel y Lankshear (2006).

- y la entrevista en profundidad (Gaitán y Piñuel, 1998; Taylor y Bogdan, 2008) al creador de los mismos, Lucas Melcón. Dicha entrevista, efectuada el 11 de octubre de 2021 por medios telemáticos, estaba basada en un cuestionario semiestructurado de 15 preguntas al que el autor podía responder con flexibilidad, incluso aportando datos sobre los que no se le habían cuestionado en un principio. Los temas de las preguntas iban desde la formación académica y profesional del entrevistado hasta la construcción de la marca y la vertiente comercial del proyecto, pasando por la estrategia comunicativa digital, los rasgos característicos de su humor y la dificultad que supone comunicar desde la periferia y, más concretamente, desde Andalucía.

\section{RESULTADOS}

Lucas Melcón es el creador de contenidos que se oculta tras Malacara (@malacarasev). Licenciado en Comunicación Audiovisual por la Universidad de Sevilla, realizó 
posteriormente dos másteres en guion y comunicación política en la misma institución, así como un curso de especialización en marketing digital en la Escuela de Organización Industrial (EOI), también en la capital andaluza. El polifacético autor ha trabajado "como fotógrafo y editor de vídeo, como diseñador gráfico, como copywriter y como community manager. A lo que me dedico en realidad es a dar una solución integral de creatividad aplicada a social media" (Melcón, comunicación personal, 11 de octubre de 2021). Su vida laboral se reparte entre empresas de telefonía, asociaciones no gubernamentales, festivales de música, restaurantes, instituciones públicas y partidos políticos: "La vida da muchas vueltas y yo he aprendido a hacer un poquito de to (sic), que se dice" (Melcón, comunicación personal, 11 de octubre de 2021).

La idea de crear sus perfiles en redes sociales surge por casualidad, "trasteando, haciendo contenido, mezclando frases de mi infancia y de mi juventud con un formato estético de la cultura pop" (Melcón, comunicación personal, 11 de octubre de 2021). Su experiencia académica y profesional ha resultado clave para dar forma a sus publicaciones:

A guionizar diálogos aprendí en el máster de guion, por ejemplo. A utilizar de manera más o menos profesional las redes me ayudó el curso de marketing. Y a comprender e ironizar con las figuras políticas puede que surgiese cuando estuve aprendiendo comunicación política (Melcón, comunicación personal, 11 de octubre de 2021).

Su aventura en redes sociales comienza a finales de 2016 creando un perfil en Facebook. Sin embargo, "el progresivo abandono de esta red por parte del público de mi edad me hizo meterme en Twitter y después en Instagram" (Melcón, comunicación personal, 11 de octubre de 2021). A inicios de 2022 acumula 321.319 seguidores (tabla 2).

Tabla 2. Perfiles sociales de Malacara

\begin{tabular}{|c|c|c|c|}
\hline & Facebook & Twitter & Instagram \\
\hline No de seguidores & 28.971 & 141.601 & 150.747 \\
\hline Cuentas que sigue & 0 (es una Fanpage) & 418 & 522 \\
\hline Publicaciones diarias & 0,5 & 5,8 & 1,2 \\
\hline Fecha de creación & noviembre 2016 & junio 2018 & enero 2017 \\
\hline
\end{tabular}

Fuente: Facebook, Twitter, Instagram. 
Pese a que en Instagram su comunidad es más amplia, es en Twitter donde Malacara centra su actividad y difunde primero sus publicaciones ya que, de hecho, los posts en Instagram y en Facebook suelen consistir en imágenes de sus tuits. Así, su estrategia digital "se basa bastante en la curación de contenido. Subo las cosas a Twitter y las que tienen más repercusión las pongo en Instagram. Las de Instagram que más me gustan las pongo también en Facebook" (Melcón, comunicación personal, 11 de octubre de 2021). Pese a ello, asevera que "no hay rutinas ni planificación de ningún tipo. No programo los posts ni me rijo por ningún tipo de horario ni de lo que convenga en términos de social media" (Melcón, comunicación personal, 11 de octubre de 2021).

La monitorización de las distintas cuentas muestra que entre el 17 de octubre y el 1 de diciembre de 2021 Twitter supuso el 70\% de sus publicaciones, seguido de Instagram $(20,6 \%)$ y de Facebook (9,4\%). Sin embargo, el rendimiento de la actividad indica que las métricas globales son mejores en Instagram, que es la red donde obtiene una mayor efectividad en términos generales (tabla 3).

Tabla 3. Actividad de los perfiles sociales de Malacara (17/10/21-01/12/21)

\begin{tabular}{|c|c|c|c|c|}
\hline & Publicaciones/día & Me gusta & Comentarios-Retuits & Reacciones \\
\hline Instagram & 4,8 & 772.512 & 8.030 & 780.542 \\
\hline Twitter & 1,4 & 510.577 & 68.467 & 579.044 \\
\hline Facebook & 0,7 & 9.876 & 749 & 28.935 \\
\hline
\end{tabular}

Fuente: Fanpage Karma.

En este periodo, las publicaciones más destacadas en cada red social se corresponden con Halloween y con el apoyo a la huelga de los trabajadores del metal en Cádiz (tabla 4). Desde una perspectiva general, los mensajes que han obtenido mayor relevancia son los que incorporan imágenes. Así, de las 10 publicaciones más destacadas, que acumulan algo más de 180.000 interacciones, 4 de ellas pertenecen a publicaciones en Twitter (83.933 interacciones) -incluidas las dos primeras- y 6 a Instagram (96.082 interacciones). Por su parte, los 10 textos y los 10 enlaces más destacados se corresponden con publicaciones de Twitter y suponen más de 45.000 y de 31.000 interacciones, respectivamente. 
Tabla 3. Mejores publicaciones de los perfiles sociales de Malacara (17/10/21$01 / 12 / 21)$

\begin{tabular}{|c|l|c|c|c|}
\hline & \multicolumn{1}{|c|}{ Publicación } & $\begin{array}{c}\text { Me } \\
\text { gusta }\end{array}$ & $\begin{array}{c}\text { Comentarios- } \\
\text { Retuits }\end{array}$ & Reacciones \\
\hline Instagram & $\begin{array}{l}\text { es xico dejenlo esta aprendiendo todavia a } \\
\text { hase cosa de buo (Imagen de un policía junto } \\
\text { a un búho) }\end{array}$ & 24.483 & 312 & 24.795 \\
\hline Twitter & $\begin{array}{l}\text { CASI PUEDE OIRSE EL SENTRIFUGAO (Imagen } \\
\text { de la Tierra iluminándose) }\end{array}$ & 51.370 & 9766 & 61.136 \\
\hline Facebook & $\begin{array}{l}\text { me gustaria que argun dia la gente de mi } \\
\text { tierra se echase a la calle porke cobramo } \\
\text { demasiao y no porque cobremo demasiao } \\
\text { poco y no porque se esten Ilevando la poca } \\
\text { industria que hay y no porque quieran que } \\
\text { nos pasemo la vida sirviendo sangria y no } \\
\text { porque er futuro que tenemo sigue mu negro } \\
\text { yno porque es una condena que nos obliga a } \\
\text { marcharno y no porque asi no se puede vivi } \\
\text { con los compañero... (imagen de Baby Yoda } \\
\text { con el texto: MANDANDOLE TODA LA } \\
\text { FUERSA A LOS COMPAÑERO DER METAL EN } \\
\text { CADI) }\end{array}$ & 1.363 & 4.617 \\
\hline
\end{tabular}

Fuente: Fanpage Karma.

Desde que en junio de 2018 crease su cuenta en Twitter, donde su biografía de perfil únicamente indica "ANDALUSIAN QUOTES", Malacara ha publicado 9.853 tuits y sus seguidores han aumentado de modo sostenido (imagen 1). La actividad de la cuenta fue más intensa en sus inicios y después, durante el año 2021, se mantuvo estable (imagen 2).

Imagen 1. Evolución de la comunidad de Malacara en Twitter.

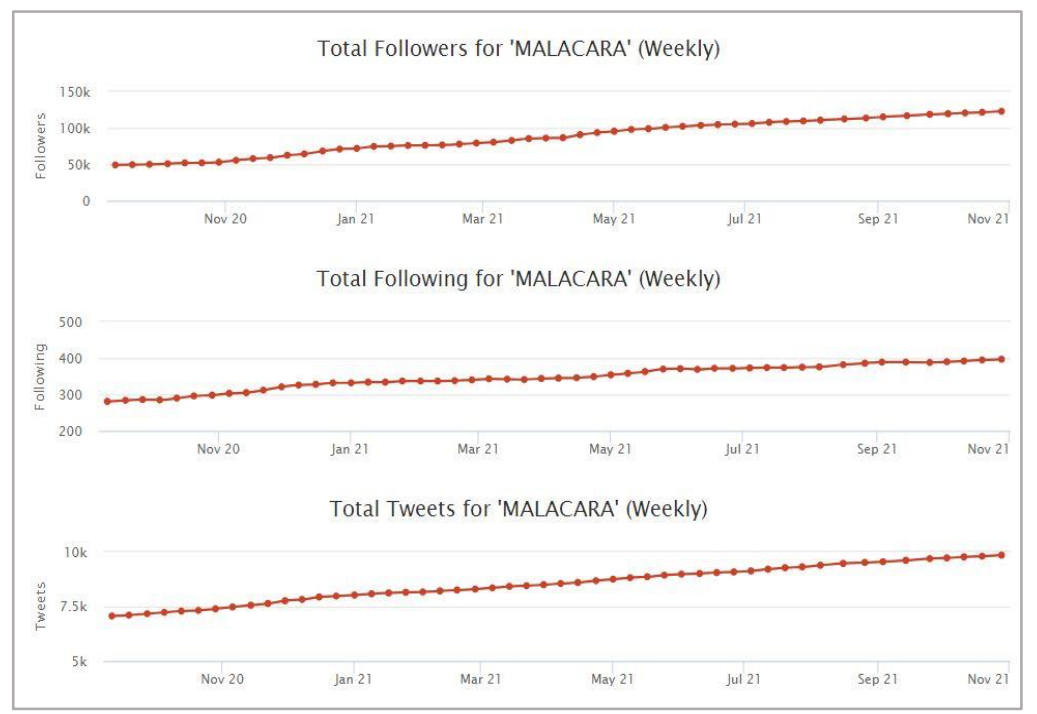

Fuente: Social Blade. 
Imagen 2. Publicaciones de Malacara en Twitter.

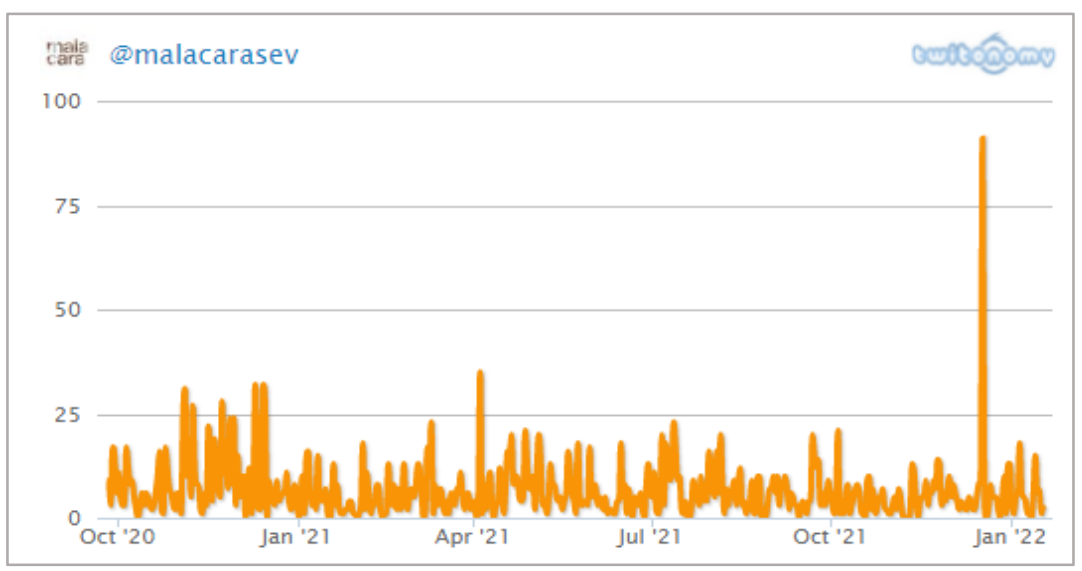

Fuente: Twitonomy.

También han evolucionado positivamente las búsquedas en Google relacionadas con la marca, tanto por su nombre genérico como asociada a la actividad en Twitter y a la venta de merchandising (imagen 3).

Imagen 3. Evolución de búsquedas en Google sobre Malacara.

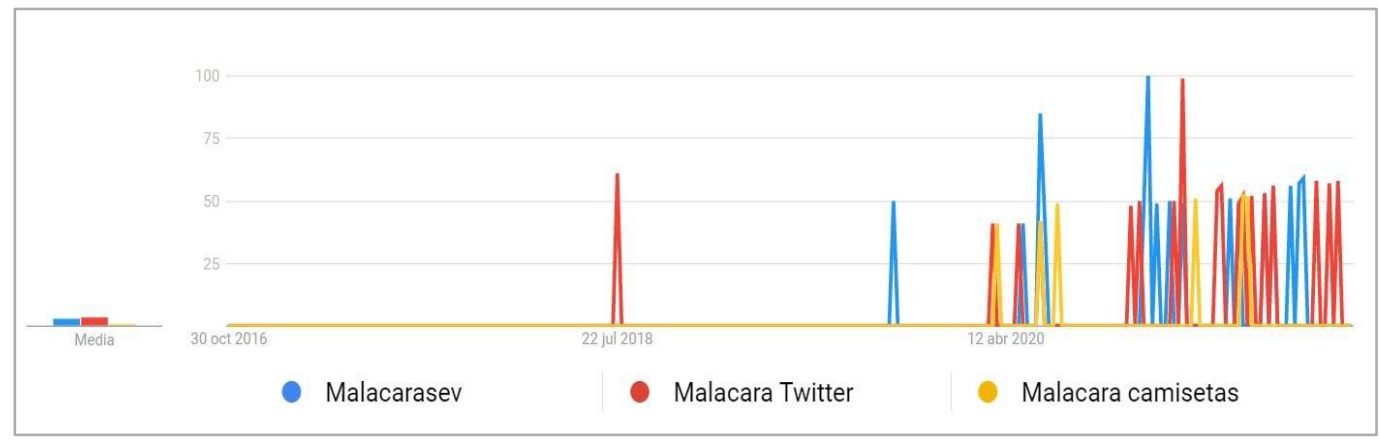

Fuente: Google Trends.

La cuenta de Twitter publica una media de 6,67 mensajes por día, manteniendo la actividad todos los días de la semana y sin una pauta horaria concreta. El $81 \%$ de sus tuits son contenido propio, mientras que el $16,2 \%$ son respuestas a otros usuarios y el $2,6 \%$ es contenido compartido. Sus publicaciones tienen unas tasas de interacción muy altas, pues el $90,75 \%$ obtiene retuiteos y el $96,84 \%$ es seleccionado como favorito. En cuanto a los numerosos comentarios y menciones que reciben sus tuits, se trata de un perfil que responde de forma directa en el $28 \%$ de los casos y que ha marcado casi 5.000 publicaciones como favoritas. 
Melcón afirma que el otro pilar de sus perfiles es el seguimiento exhaustivo de la actualidad cotidiana, tanto en los medios convencionales como en las plataformas sociales. En el último año ha publicado sobre temas tan diversos como la reforma laboral y el enfrentamiento entre socios de gobierno, las comparecencias del comisario José Manuel Villarejo relacionadas con la corrupción política, la erupción del volcán en Canarias, la subida del precio de la electricidad, la caída de Facebook, la detención de Carles Puigdemont, la problemática de la contaminación del Mar Menor, conflictos laborales como el de los riders contra las multinacionales o la huelga de los trabajadores del metal, la crisis del Coronavirus o asuntos de corte social relacionados con el feminismo, la homofobia y el racismo.

Las temáticas que emplea de forma más habitual (gráfico 1) son asuntos de la vida cotidiana - desde dejar abierto un producto que se estropea a no querer ir al colegio, pasando por salir de fiesta o discutir con la familia-, contenido político abordado desde el humor crítico - que focaliza en las instituciones, los partidos políticos e incluso en la Corona-, la cultura andaluza - gastronomía, costumbres, arquetipos...- y parodias de referentes de la cultura popular como futbolistas, cantantes, celebridades o productos audiovisuales - Harry Potter, El Señor de los Anillos o La Guerra de las Galaxias-. Atendiendo a la tipología de memes utilizada en la tabla de análisis, se comprueba que Malacara emplea memes de las categorías comentario social y político, humor absurdo y bromas de diversas subculturas. Sin embargo, es relevante destacar que la cuenta no resignifica memes ya existentes, sino que los crea aplicando los recursos expresivos y narrativos que conforman su lenguaje característico. Además, es igualmente reseñable que el meme no es el único formato de humor que emplea, puesto que más de un cuarto de sus publicaciones se basan solamente en texto. 
Gráfico 1. Temáticas empleadas en Twitter por Malacara.
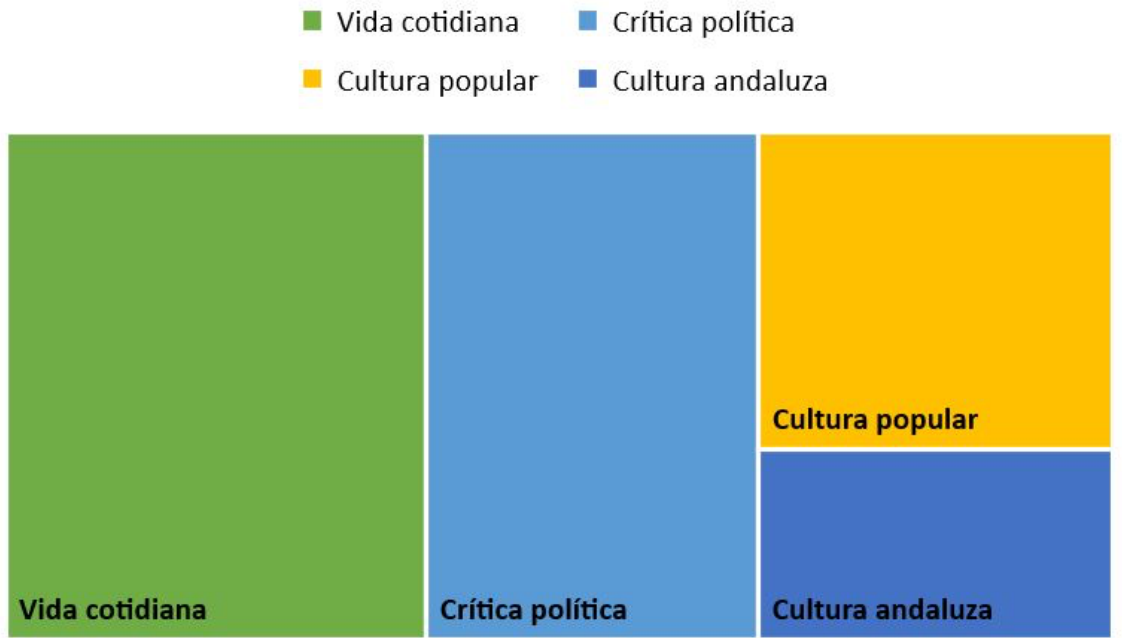

Fuente: elaboración propia.

Malacara expresa su opinión sobre asuntos de índole política, social y cultural que estén presentes en la agenda de los medios de comunicación o sobre los que haya algún tipo de debate en la opinión pública. Mediante sus publicaciones queda patente el posicionamiento ideológico del autor, que se identifica con el espectro político de izquierdas e imprime a sus contenidos un cariz crítico y reivindicativo, pero siempre con un tono humorístico. De este modo, entre otros asuntos, se ha pronunciado sobre la reforma laboral, la expropiación a los bancos, el apoyo al movimiento obrero, el capitalismo, el rechazo a los partidos de derechas, los recortes en sanidad y en educación, la gestión de la pandemia o la situación de la realeza.

Las publicaciones que más engagement han generado (imagen 4), tanto al ser retuiteadas como por recibir marcaciones como favorito, son las referentes a la subida del precio de la electricidad en España, una pieza humorística sobre Halloween, una crítica al ayuno intermitente, un juego de palabras con uno de los protagonistas de Eurovisión que se convirtió en meme y una publicación sobre la polémica por la asistencia del presidente del Partido Popular, Pablo Casado, a una misa en honor al dictador Francisco Franco. 
Imagen 4. Publicaciones con más impacto en Twitter de Malacara.
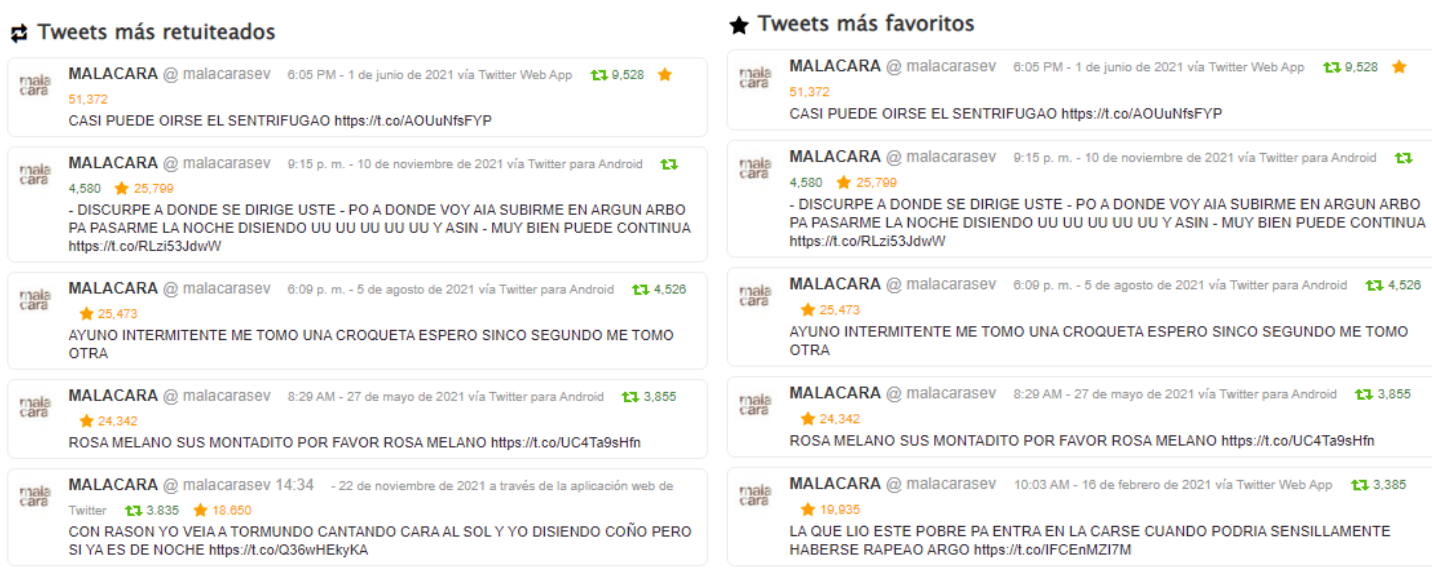

Fuente: Twitonomy.

A nivel formal, las publicaciones de Malacara poseen dos rasgos característicos principales: el uso de las mayúsculas en los textos y la utilización del dialecto andaluz concretamente, el de su variante sevillana - como vehículo de expresión (imagen 5). En lo concerniente al primero de ellos, "lo de las mayúsculas en un principio se emplea solo en la versión de Twitter y los pantallazos, y tiene como objetivo imitar de alguna manera los memes clásicos con letra IMPACT" (Melcón, comunicación personal, 11 de octubre de 2021). En lo referido al dialecto, "es para hacerlo fonético y natural. Al final, es una variante que es andaluza y a la vez no, y sevillana y a la vez tampoco. Es el idioma que se ha ido creando" (Melcón, comunicación personal, 11 de octubre de 2021). Por ello, los textos no siguen la ortografía normativa a propósito con la intención de imitar las particularidades del dialecto; sin embargo, no es extraño que las publicaciones reciban críticas por sus errores ortográficos por parte de usuarios que desconocen la idiosincrasia de la propia cuenta. 
Imagen 5. Ejemplos de publicaciones en Twitter de Malacara.
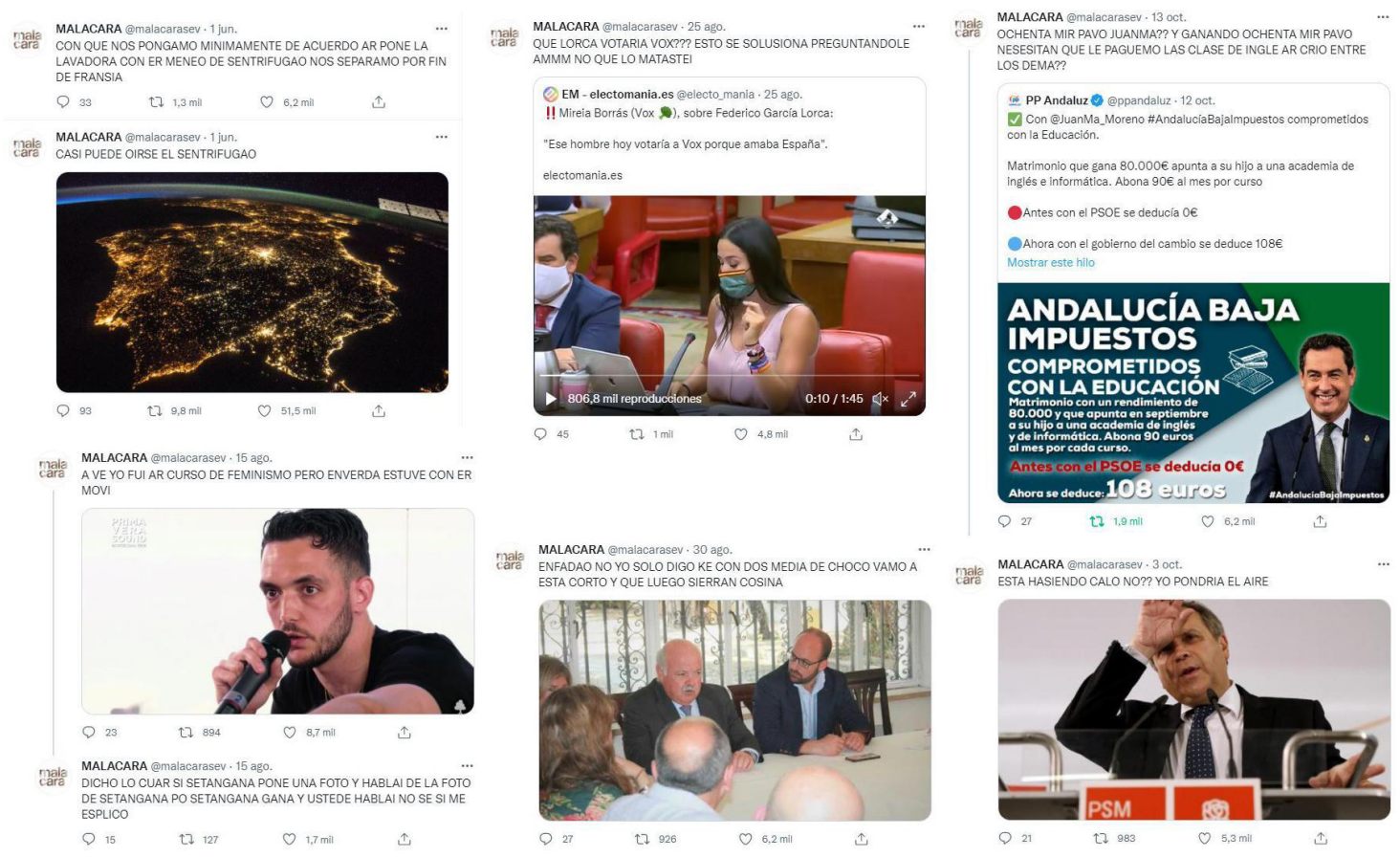

Fuente: Twitter.

Los recursos discursivos que emplea Malacara, además de por lo ya mencionado, se caracterizan por la prevalencia de la imagen y por sus referencias al imaginario colectivo y a la cultura popular. Así, el $45 \%$ de los tuits incluye imágenes, el $27 \%$ enlaces, el $26 \%$ de las publicaciones emplean únicamente texto y el $2 \%$ incorporan enlace e imagen. Utiliza mayoritariamente imágenes fijas únicas, normalmente fotografías que incorpora de forma individual a cada tuit. Los tuits únicamente textuales contienen mensajes breves y concisos que no requieren de apoyo visual, salvo en un tipo de contenido propio como son las parodias de guiones audiovisuales. En estos casos el autor elabora publicaciones textuales con el texto de los guiones pero que se incorporan como imagen en las publicaciones, para poder mantener el formato visual propio de estas piezas. No se detecta una presencia relevante de recursos muy habituales en Twitter, como son llamadas a la acción, emoticonos, encuestas o etiquetas.

Las imágenes que emplea son muy variadas, pero destacan por su abundancia las de personajes conocidos - fundamentalmente políticos-, las de animales y las de personajes de ficción, normalmente pertenecientes al mundo audiovisual (imagen 6). 
Imagen 6. Ejemplos de publicaciones en Twitter de Malacara.

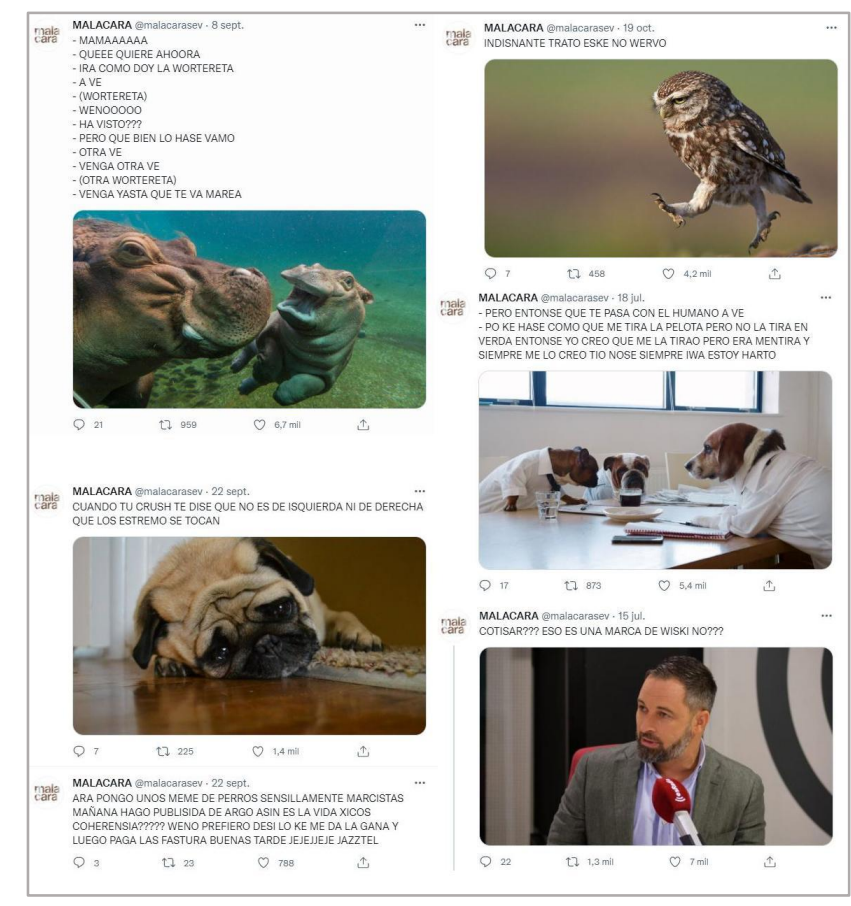

Fuente: Twitter

Por otra parte, también utiliza imágenes secuenciales que organiza a través de la herramienta de creación de hilos de Twitter, aunque lo habitual es que en estos casos sean fotogramas de productos culturales reconocibles para el público -desde películas clásicas hasta series actuales - sobre los que parodia los diálogos mediante títulos gráficos. Los vídeos, por su parte, son empleados en menor medida y suelen ser de animales sobre los que subtitula supuestos diálogos humorísticos, frecuentemente relacionados con la vida cotidiana.

El estilo de las publicaciones se caracteriza por el empleo de un lenguaje coloquial en tono humorístico. Es habitual que evite la mención expresa a la cuestión que parodia o critica, jugando con la complicidad del público que lee el subtexto a través del uso connotativo de los recursos visuales. De este modo, abundan imágenes y personajes de películas y series — desde Baby Yoda a Pingu-, videojuegos, el mundo del deporte y la vida política y social. Otra estrategia recurrente es la descontextualización de las imágenes, especialmente las de referentes políticos, para crear contrastes basados en la yuxtaposición de elementos inconexos. Como se ha señalado al explicar las temáticas de las publicaciones, es reseñable la alta carga de crítica política que contiene la cuenta, 
tanto hacia medidas y actuaciones concretas como hacia posicionamientos ideológicos de derechas (imagen 6).

Melcón termina de perfilar el aspecto formal de sus publicaciones del siguiente modo: "intento que todo el contenido tenga un apoyo visual importante y que sea coherente con el texto. Y que el texto siempre sea humorístico e irónico" (Melcón, comunicación personal, 11 de octubre de 2021).

El acento no es una cuestión baladí para el autor, puesto que se sintió en ocasiones incomprendido durante la etapa laboral que desarrolló en Madrid:

En Madrid, a veces, parece que tienen cera en los oídos. A mí se me entiende perfectamente, pero allí, en ocasiones, tenía que repetir las cosas un par de veces. No sé si es porque son duros de oído o porque se niegan a hacer el mínimo esfuerzo de escucha activa (Melcón, comunicación personal, 11 de octubre de 2021).

Por ello, se siente más cómodo comunicando desde la periferia, e incluso atribuye a este hecho parte de su éxito: “Afortunadamente y esperemos que dure mucho, resido en mi ciudad, Sevilla, desde hace ya dos años, tras haber pasado otros dos años y medio allí. Coincidentes, por cierto, con la explosión de la página. Igual tuvo que ver" (Melcón, comunicación personal, 11 de octubre de 2021). El otro factor que ha contribuido a que se convierta en una celebridad en las redes sociales es, a su juicio, la honestidad: "no engaño a nadie, creo. Soy natural" (Melcón, comunicación personal, 11 de octubre de 2021).

Por otra parte, los comentarios negativos que se vierten en sus perfiles los gestiona "bloqueando porque me entristecen mucho. Intento no contestar ni entrar y, a veces, ni leer. Internet está lleno de gente con miedos, problemas y envidias y en ocasiones se convierte en un lugar hostil" (Melcón, comunicación personal, 11 de octubre de 2021). También ha tenido que hacer frente a otras polémicas, como la surgida con el periodista Emilio Doménech a raíz de la cobertura informativa que este último realizó de las elecciones presidenciales estadounidenses de 2020. Dicho redactor empezó a hacer 
referencia en sus directos a los memes que Malacara popularizó en la red sobre su figura, pero sin mencionar la autoría de los mismos:

Con él no tengo ningún tipo de problema. Sencillamente señalé, y él se dio cuenta perfectamente, que se hizo hasta trending topic una cosa que yo había puesto en marcha. A la polémica se sumó la marca que puso "DOMENE" en una camiseta; eso me molestó bastante. Al final acabó retirando la camiseta y haciéndose la víctima (Melcón, comunicación personal, 11 de octubre de 2021).

Y es que Melcón se ha adentrado en el terreno del merchandising (imagen 7) con su propia línea de ropa: "Las camisetas y demás aportan un poco la fisicidad a la marca, que hace que salga de la pantalla y esté en las calles. Me ha hecho mucha ilusión ver a tantísima gente con mis camisetas" (Melcón, comunicación personal, 11 de octubre de 2021). Sus mensajes han traspasado la barrera de lo digital para llegar al mundo físico a través de la mercadotecnia, dándole un componente transmedia a los mismos:

\section{Imagen 7. Merchandising de Malacara.}
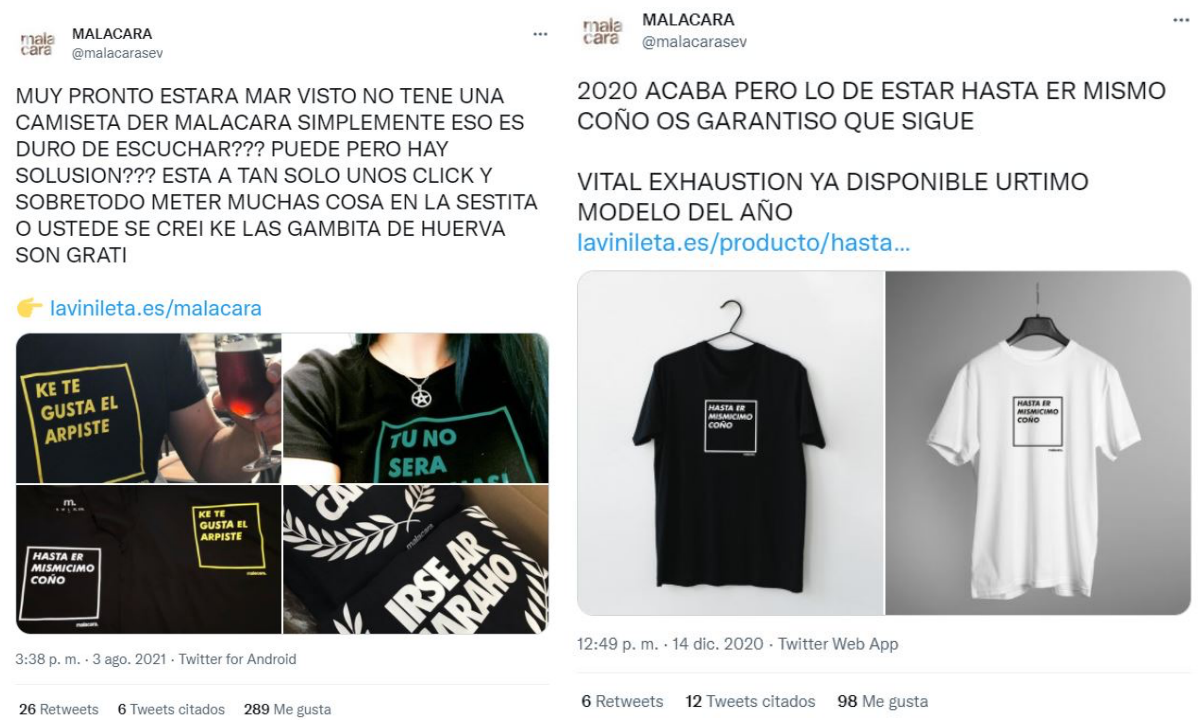

Fuente: Twitter

Respecto a la preservación de su anonimato, asegura que le "daría bastante pereza y vergüenza que me hablen personas que no conozco por la calle. [...] No quiero ser famoso porque lo que más valoro en esta vida es la tranquilidad, por encima del dinero y de cualquier otra cosa" (Melcón, comunicación personal, 11 de octubre de 2021). 
Además, esta decisión le permite gestionar sus cuentas en redes como si de una marca se tratase:

Mi pasión por los límites de la comunicación corporativa hace que me resulte más atractiva la idea de proyectar todo como una especie de marca más que como una persona. Precisamente en la disonancia entre lo reglado de lo estético de la marca y lo improvisado de la escritura nace parte del encanto que creo puede tener (Melcón, comunicación personal, 11 de octubre de 2021).

Por último, las expectativas de futuro del proyecto Malacara trascienden los límites de las redes sociales: "Colaboro en la radio desde hace un tiempo y también he tenido alguna columna en eldiario.es, entre otros. Pero siempre estoy abierto a más colaboraciones y nuevas fronteras" (Melcón, comunicación personal, 11 de octubre de 2021).

\section{DISCUSIÓN Y CONCLUSIONES}

Siguiendo la definición de Martínez-Rolán y Piñeiro-Otero (2016), el universo de Malacara está compuesto por frases, tendencias, imágenes fijas, vídeos, etc. que se transforman en organismos vivos y que trascienden su alcance y su significado, incluso cuando son extraídos, como en este caso, de su contexto original. La observación de una sola de sus publicaciones "permite entender la estructura sociocultural de los individuos inmersos dentro de una cultura digital" (Islas, 2020, p. 46), concretamente la actualidad española e internacional reflejada en los social media. En cuanto a los temas que abordan sus memes, son tan extensos como la literatura académica que ha tratado el género humorístico: de la política (Sierra, 2012; Fuica González, 2013; Martínez Rolán y Piñeiro Otero, 2017; Pérez Pereiro y Campos, 2019; Maciá y Rissotto Britos, 2020) a la pandemia de la COVID-19 (Sola-Morales, 2020; Kral'ovičová, 2020), pasando por el periodismo y la comunicación audiovisual (Alvarado Ortega y Ruiz Gurillo, 2013; Weitz, 2016; Fraticelli, 2019), la cultura (Islas, 2020; Llosa Sanz, 2020) o la identidad concretamente, la andaluza- (Pérez Salazar, 2017; Sánchez-Gey, 2021). Así, en su cuenta aparecen Pedro Sánchez, Juan Manuel Moreno Bonilla, Yolanda Díaz, Donald Trump, Hitler, Sergio Ramos, Gandalf, los Simpson, Peppa Pig, Jeff Bezos, Måneskin, Paquirrín o C. Tangana, entre otros muchos personajes. De este modo, construye 
contenido textual humorístico y memes coincidentes con las categorías de comentario social y político, humor absurdo y bromas de diversas subculturas planteadas por Knobel y Lankshear (2006, p. 218).

El humor que el autor vierte en sus distintos perfiles de redes sociales está marcado, como el propio Lucas Melcón declara, por la tradición oral y el habla andaluza que formó parte de su infancia y juventud $-y$ ahora también de su presente-. Por tanto, su obra es también una reivindicación de la cultura andaluza en los términos empleados por Moreno (2008) y de una forma de comunicar desde la periferia. A ello ha añadido sus conocimientos sobre la cultura popular de su generación, así como su bagaje profesional en el ámbito de la comunicación - concretamente en lo que concierne a las labores de gestión de redes sociales y comunicación corporativa- para configurar una voz propia que, de manera indeleble, se aprecia en todas sus publicaciones y que se ha expandido al mundo físico a través del merchandising en un ejemplo de estrategia transmedia.

Además de por el uso dialectal del lenguaje escrito, con el empleo de las mayúsculas a modo de interpelación al usuario digital, sus posts se caracterizan por imágenes normalmente fijas - descontextualizadas que completan no solo el significado, sino también el impacto visual que buscan provocar, huyendo de otros artificios expresivos que ponen a su disposición las propias redes sociales (retoque digital de imagen, emoticonos, hashtags, etc.). Las publicaciones que utilizan vídeo o únicamente texto son minoritarias, aunque siguen la pauta discursiva descrita con anterioridad. Los textos no siguen la ortografía española normativa, empleando un remedo de escritura fonética del dialecto andaluz que hace su estilo muy reconocible por sus seguidores.

Podemos establecer, asimismo, tres grandes grupos de publicaciones: las basadas en imágenes de representantes políticos, las que poseen elementos reconocibles de la cultura popular (cine, series de ficción, presentadores televisivos, cantantes de moda, etc.) y las de temática natural-animal, que le sirven para replicar en ellas diálogos de la vida cotidiana. En todos ellos, la experiencia personal de Melcón vuelve a jugar un papel decisivo: su formación en comunicación política, sus amplios conocimientos sobre la 
actualidad y las tendencias - no solo en redes sociales - y su crianza entre frases hechas propias del habla andaluza.

Al respecto de la estrategia comunicativa digital, precisamente está caracterizada por ese exhaustivo seguimiento de la actualidad que le impide perder vigencia, pese a la aparente anarquía en cuanto a tiempos y ritmos de publicación. Su plataforma base es Twitter donde el creador encuentra una audiencia más parecida a él mismo en cuanto a edad, gustos e intereses - y de ahí deriva contenido hacia Facebook e Instagram mediante una labor de curación ejercida sobre aquellas publicaciones que obtienen más interacciones.

Por todo lo expuesto, podemos afirmar que esta investigación, a pesar de tratarse de un estudio de caso con las limitaciones propias de este diseño metodológico, ha alcanzado todos sus objetivos, ya que se han expuesto las características del discurso humorístico de Malacara en sus publicaciones, así como los rasgos expresivos que las distinguen, los temas que abordan y la estrategia digital que se sigue en las diferentes redes sociales. El presente trabajo constata que los creadores de contenido pueden emplear el humor, el uso dialectal del lenguaje y la crítica política y social como herramientas para generar comunidad en el ámbito digital. De este modo, encontrar una voz propia que caracterice el discurso de forma coherente y cohesionada contribuye a construir una marca reconocible que fidelice a la audiencia. Por otra parte, adaptar sus mensajes al lenguaje de cada red social y desarrollar una curación sobre los propios contenidos facilita la eficiencia e incrementa el rendimiento de las publicaciones.

Igualmente, el objeto de estudio que aquí se aborda constituye un tema de gran interés que puede continuar su desarrollo mediante futuras líneas de investigación, como son los contenidos humorísticos en las nuevas plataformas - Twitch, TikTok, etc. - o las posibilidades que ofrece el ámbito digital para romper estereotipos identitarios a través del humor.

\section{REFERENCIAS BIBLIOGRÁFICAS}

Akbar, T. A. y El-Gohary, H. (2021). Brand Humour Advertisements on a Social Network Platform and Their Impact on Online Consumer Engagement: The Case of Instagram. 
En El-Gohary, H., Edwards, D. y Ben Mimoun, M. S. (ed.). Handbook of Research on IoT, Digital Transformation, and the Future of Global Marketing, (pp. 212-236). Hershey: IGI Global.

Alarcón, V. (2017). Humorismo como creación y fortalecimiento de los vínculos en la sociedad red: el caso de los memes sobre filósofos. Revista de comunicación, 16(1), 122-146.

Álvar, V. M. (1962). Fonética y fonología andaluzas. Revista de filología española, 45(1/4), 227-240.

Alvarado Ortega, M. B. y Ruiz Gurillo, L. (2013). Humor, ironía y géneros textuales. Universidad de Alicante.

Anduaga, U. (1 de abril de 2017). ¿Los vascos se ríen de sí mismos? Consecuencias políticas del humor en la construcción de la nación y la identidad vasca. Congreso Internacional de Ciencias Sociales. Universidad Rey Juan Carlos. Madrid, España.

Arango, L. (2015). Una aproximación al fenómeno de los memes en Internet: claves para su comprensión y su posible integración pedagógica. Comunicação Mídia e Consumo, 12(33), 110-132. http://dx.doi.org/10.18568/cmc.v12i33.677

Ballesteros, E. (2016). Circulación de memes en WhatsApp: ambivalencias del humor desde la perspectiva de género. Empiria: Revista de metodología de ciencias sociales, (35), 21-45.

Bardin, L. (1991). Análisis de contenido. Madrid: Ediciones Akal.

Benjamin, W. (2021). La obra de arte en la época de su reproductibilidad técnica. Madrid: Flash.

Brennan, L., Parker, L., Nguyen, D. y Pochun, T. (2020). Positive emotions in social marketing and social advertising using humour. En Parker, L. y Brennan, L. (ed.). Social Marketing and Advertising in the Age of Social Media, pp. 102-119. Londres: Edward Elgar Publishing. https://doi.org/10.4337/9781786434678.00014 
Camas, L., Valero, A. y Vendrell, M. (2018). "Hackeando memes": Cultura democrática, redes sociales y educación. Espiral. Cuadernos del Profesorado, 11(23), 120-129.

Carratalá, A. (2015). El tratamiento de la Monarquía española en las viñetas de los medios digitales, Dígitos: revista de Comunicación Digital, (1), 127-154. http://dx.doi.org/10.7203/rd.v0i1.7

Castro-Higueras, A., Torres-Martín, J. L., Carballeda-Camacho, M., y de AguileraMoyano, M. (2021). Comunicación, salud y Covid-19. Cómo comunican los instagrammers sanitarios españoles. Ámbitos. Revista Internacional De Comunicación, (53), 42-62. https://doi.org/10.12795/Ambitos.2021.i53.03

Castro-Martínez, A. y Díaz-Morilla, P. (2021). Tuiteratura: contar historias con los hilos y recursos de Twitter. Ocnos. Revista De Estudios Sobre Lectura, 20(1), 82-95. https://doi.org/10.18239/ocnos_2021.20.1.2481

Colle, R. (2011). El análisis de contenido de las comunicaciones. La Laguna: Sociedad Latina de Comunicación Social.

Davison, P. (2012). The Language of Internet Memes. En Mandiberg, M. (Ed.). The Social Media Reader (pp. 120-136). New York: New York University Press.

Dawkins, R. (1976). The selfish gene. Oxford: University Press.

Díaz Bizkarguenaga, K. (2015). FaceGUK: la construcción social de la identidad vasca analizada desde la etnografía digital. Athenea Digital. Revista de pensamiento e investigación social, 15(2), 275-288.

Emerson, C. (2018). The first hundred years of Mikhail Bakhtin. Princeton: University Press.

Fraticelli, D. (2019). Los colectivos mediáticos de las redes. Algunas observaciones desde el humor ¿y más allá? InMediaciones de la Comunicación, 14(1), 47-63. https://doi.org/10.18861/ic.2019.14.1.2885 
Fuica González, C. (2013). El discurso político de resistencia en las redes sociales: el caso de los memes desde una perspectiva crítica y multimodal. Contextos, 30, pp. 37-48.

Gaitán, J. A. y Piñuel, J. L. (1998). Técnicas de investigación en comunicación social. Elaboración y registro de datos. Madrid: Síntesis.

García Huerta, D. (2014). Las imágenes macro y los memes de internet: posibilidades de estudio desde las teorías de la comunicación. PAAKAT: Revista de Tecnología y Sociedad, 6(4).

Genette, G. y Prieto, C. F. (1989). Palimpsestos. Madrid: Taurus.

González Álvarez, C. (2003). La intertextualidad literaria como metodología didáctica de acercamiento a la literatura: aportaciones teóricas. Lenguaje y textos, 21, 115-128.

González Oñate, C. y Martínez Sánchez, A. (2020). Estrategia y comunicación en redes sociales: Un estudio sobre la influencia del movimiento RealFooding. Ámbitos. Revista Internacional de Comunicación, (48), 79-101.

https://dx.doi.org/10.12795/Ambitos.2020.i48.05

Gutiérrez Lozano, J. F., y Cuartero, A. (2020). El auge de Twitch: nuevas ofertas audiovisuales y cambios del consumo televisivo entre la audiencia juvenil. Ámbitos. Revista Internacional de Comunicación, 50, 159-175. https://doi.org/10.12795/Ambitos.2020.i50.11

Hernanz, F. P. y Hernanz, J. L. P. (2012). \#Socialholic: Todo lo que necesitas saber sobre marketing en medios sociales. Barcelona: Gestión 2000.

Holton, A. E. y Lewis, S. C. (2011). Journalists, social media, and the use of humor on Twitter. Electronic Journal of Communication, 21(1/2), 1-22.

Sánchez-Gey, N. (2021). La televisión pública andaluza y la imagen proyectada en las redes sociales. En Mancinas-Chávez, R. y Cárdenas-Rica, M. L. Medios y comunicación en tiempos de posverdad (pp. 130-146). Madrid: Fragua 
Imlawi, J. y Gregg, D. (2014). Engagement in online social networks: The impact of selfdisclosure and humor. International Journal of Human-Computer Interaction, 30(2), 106-125. https://doi.org/10.1080/10447318.2013.839901

Islas, A. (2020). Memes como Símbolos de Transmisión Cultural: Los Memes de las Redes Sociales. Huella de la Palabra, (14), pp. 28-49.

https://doi.org/10.37646/huella.v14i14.14

Jenkins, H. (2010). Transmedia storytelling and entertainment: An annotated syllabus. Continuum, 24(6), pp. 943-958. https://doi.org/10.1080/10304312.2010.510599

Knobel, M. y C. Lankshear (2006). Online Memes, Affinities, and Cultural Production. En Knobel, M. y Lankshear, C. (eds). A New Literacies Sampler (pp. 199-227). Berna: Peter Lang.

Kral'ovičová, D. (2020). Humour and social networks during COVID-19. Marketing Identity, 8(1), 300-307.

Kristeva, J. (1969). Bakhtine, le mot, le dialogue et le roman. Critique, 239, 438-467.

Llosa Sanz , A. (2020). De microrrelatos y memes literarios en las redes sociales: estrategias de edición digital en la minificción multimodal. Microtextualidades. Revista Internacional De Microrrelato y Minificción, (7), 26-45.

https://doi.org/10.31921/microtextualidades.n7a2

Maciá, L. y Rissotto Britos, S. V. (2020). Conversación política en plataformas digitales: parodias, animación japonesa y dispositivos. Questión, 2(66), 1-30.

https://doi.org/10.24215/16696581e495

Mancera Rueda, A. (2014). El sexismo como blanco del humor en las redes sociales. Feminismo/s, 24, 163-192. http://dx.doi.org/10.14198/fem.2014.24.08

Mancera Rueda, A. (2016). Usos lingüísticos alejados del español normativo como seña de identidad en las redes sociales. Bulletin of Spanish Studies, 93(9), 1469-1493. https://doi.org/10.1080/14753820.2016.1181435 
Martínez-García, L. (2009). La contribución del humor, de la comedia de situación a la identidad cultural catalana. Comunicación y sociedad, 22(1), 223-241.

Martínez-Rolán, X. y Piñeiro-Otero, T. (2016). The use of memes in the discourse of political parties on Twitter: analyzing the 2015 State of the Nation Debate. Communication \& Society, 29(1), 145-160. DOI: 10.15581/003.29.1.145-159

Martínez-Rolán, X. y Piñeiro-Otero, T. (2017). El uso de los memes en la conversación política 2.0. Una aproximación a una movilización efímera. Prisma Social, (18), 55-84. Meléndez Malavé, N. (2010). Morfología de los espacios de humor gráfico en diarios iberoamericanos de referencia. En Ludec, N. y Sarría Buil, A. (coords) La morfología de la prensa y del impreso: la función expresiva de las formas: Homenaje a Jean-Michel Desvois (pp. 309-326). Paris: PILAR (Presse, Imprimés, Lecture dans l'Aire Romane).

Mogin-Martin, R. (2006). La monarquía española según la revista" El Jueves": análisis de la antología" Tocando los Borbones". En Chaput, M-C y Peloille, M. (coord) Humor y política en el mundo hispánico contemporáneo (pp. 115-132). Paris: PILAR (Presse, Imprimés, Lecture dans l'Aire Romane).

Moreno, I. (2008). La identidad cultural de Andalucía: aproximaciones, mixtificaciones, negacionismo y evidencias. Centro de Estudios Andaluces.

Morgan, L. (2019). La irradiación como programa prometeico: Walter Benjamin, la copia y la reproducción técnica. En IX Jornadas de Investigación en Disciplinas Artísticas y Proyectuales, Universidad Nacional de La Plata.

Mosquera Álvarez, M. C. e Hidalgo Albuja, P. E. (2020). ¿Lo divertido se recuerda?: Humor como recurso para reducir la evasión publicitaria en redes sociales. Revista Scientific, 5(18), 213-233. https://doi.org/10.29394/Scientific.issn.2542-

2987.2020.5.18.11.213-233

Narbona Jiménez, A. (1986). Problemas de sintaxis coloquial andaluza. Revista española de lingüística, 16(2), 229-276. 
Nevado, I. (2020). La programación de La Sexta. De la variedad de contenidos al triunfo del infoshow. (2006-2010). Estudios sobre el Mensaje Periodístico, 26(2), 693-702. http://dx.doi.org/10.5209/esmp.67804

Padilla Castillo, G. (2016). Redes sociales institucionales de éxito: los casos de @policia y @guardiacivil en España. Opción: Revista de Ciencias Humanas y Sociales, (12), 85-109.

Pano Alamán, A. y Mancera Rueda, R. (2014). Identidades falsas en Twitter: la ironía y el humor verbal como mecanismos paródicos. Discurso \& Sociedad, 8(3), 507-536.

Pérez-Pereiro, M. y Romay-Campos, J. (2020). Humor transgresor y discurso extremo en las redes sociales: La respuesta del fandom de PewDiePie a la polémica de \#killalljews. Revista De La Asociación Española De Investigación De La Comunicación, 7(13), 118-139. https://doi.org/10.24137/raeic.7.13.6

Pérez Salazar, G. (2017). El meme en Internet. Identidad y usos sociales. México, D. F.: Fontamara.

Ramírez, M. G. (2018). El uso de YouTube en el Procés catalán. Comunicación política a través de los social media: ¿prosumidores mediatizados?. Estudios sobre el mensaje periodístico, 25(1), 213-234. http://dx.doi.org/10.5209/ESMP.63725

Requejo Fraile, M., Velasco Molpeceres, A. M. y Reguero Sanz, I. (2016). El humor gráfico español ante el referéndum escocés del 18 de septiembre de 2014. ¿Dibujando la independencia de Cataluña?. Historia y Comunicación social, 21(1), 15-37. http://dx.doi.org/10.5209/rev_HICS.2016.v21.n1.52683

Rey, J. P. (2020). Tik Tok mucho más que bailecitos y centennials. Interactiva: Revista de la comunicación y el marketing digital, (190), pp. 56-63.

Scolari, C. A. (2020). Cultura snack. Buenos Aires: La Marca Editora.

Shifman, L. (2012). An anatomy of a YouTube meme. New media \& society, 14(2), 187-203. 
Sierra, S. (2012). Humor y crítica social en la red en el entorno del 15M. Discurso \& Sociedad, 6(3), 611-635.

Sola-Morales, S. (2020). Humor en tiempos de pandemia. Análisis de memes digitales sobre el coronavirus. ZER: Revista De Estudios De Comunicación = Komunikazio Ikasketen Aldizkaria, 25(49). https://doi.org/10.1387/zer.21817

Taylor, S. J. y Bogdan, R. (2008). La entrevista en profundidad. Métodos cuantitativos aplicados, 2, 194-216.

Valiente Alber, S. (2016). Marcas sonrientes: humor y engagement en publicidad. Barcelona: Editorial UOC.

Vásquez, C. (2019). Language, creativity and humour online. Londres: Routledge. Vickery, J.R. (2014). The curious case of Confession Bear: the reappropriation of online macro-image memes. Information, Communication \& Society, 17(3), 301-325.

Weitz, E. (2016). Humour and social media. The European Journal of Humour Research, 4(4), 1-4. http://dx.doi.org/10.7592/EJHR2016.4.4.weitz

Wimmer, R. D. y Dominick, J. R. (1996). La investigación científica de los medios de comunicación: una introducción a sus métodos. Barcelona: Bosch.

Yin, R. (1994). Applications of case study research. Londres: Sage Publishing. 